non-traumatic accidents such as near drownings, burnings, and electrocutions. The immediate management priorities are similar in both groups," so there is nothing to be gained by dividing them between two specialties. Resuscitation of injured patients is the forte of the accident and emergency specialist. How well it is being carried out will become apparent through studies of the outcome of trauma and audit systems in which accident and emergency staff are prominent participants.

PATRICK A NEE

Department of Accident and Emergency.

Derbyshire Roval Infirmary,

Derby DE1 2QY

1 Nee PA. Surgeons and trauma carc. Br. Med f 1989;299:323-4.

(29 July.)
2 Dykes EH. Surgeons and trauma care. Br.Med f 1989:299:513. (19 August.)

3 Royal College of Surgeons of England. The management of patients with major injuries. London: RCS, 1988

4 West JG, Trunkey DD, Lim RC. Systems of trauma care. Study of two counties. Arch Surg 1979;114:455-60.

5 Spence HT, Redmond AD, Edwards JD. Trauma audit-the use of TRISS. Health Trends 1988;20:94-7.

6 Snook R. Principles of primary care of the injured. In: Dudley HAF, ed. Hamilton Bailey's emergency surgerv. Bristol: W'right. 1986:40-51

\section{Sensible guidelines on immunisation}

SIR,-Dr D P Addy quotes with approval the recently published guidelines for immunisation against pertussis.' The British Paediatric Association suggests that all children should be immunised except those suffering from an acute febrile illness and those who have had a severe local or general reaction to a previous immunisation, including pertussis. The datasheet produced by Wellcome and distributed with the vaccine to the immunisation clinics by the health service states clearly that "The administration of pertussiscontaining vaccines is contraindicated in children with a history or a family history of convulsions, epilepsy, cerebral irritation in the neonatal period or any other disorder of the central nervous system. Children with evidence of an infection or severe allergy should not be vaccinated." A general practitioner would find it hard to ignore the clear cut advice from the manufacturer. I suggest a way out. The NHS Management Board should follow the example of the larger stores-for example, Sainsbury's and Marks and Spencer-and distribute the vaccine under its own label with a datasheet listing only the contraindications agreed by the Joint Committee on Vaccination and Immunisation. The general practitioners will cease to be confused. The public will know that the NHS is accepting full responsibility for the advice its general practitioners are receiving on the correct use of what is, after all, a drug.

J K ANAND

Peterborough Health Authority.

Peterborough PEI ILN

1 Addy DP. Sensible guidelines on immunisation. Br Med $\mathrm{J}$ 1989;299:516-7. (19 August.

\section{Cocaine and crack}

SIR, - There is an important error in the otherwise excellent editorial by Dr John Strang and Professor Griffith Edwards.' Discussing pharmacological approaches to the treatment of cocaine abuse, they state: "A drug might be given which would produce cocaine blockade (just as naltrexone does with heroin), but no such drug has yet been reliably identified." It is true that we do not yet have an equivalent of naltrexone for cocaine abuse, but we do have an equivalent of disulfiram in the form of monoamine oxidase inhibitors such as phenelzine.
There are, of course, important pharmacological differences between a substance which blocks the actions of a drug and one which sensitises the body to it, but at a psychological level blocking drugs like naltrexone and sensitising drugs like disulfiram work in very much the same way. Both of them deter drug abuse by the threat of an unpleasant reaction. In the case of disulfiram the unpleasantness is physical. With naltrexone it is psychological: the abuser finds that taking an attractive drug, acquired with difficulty and expense, produces none of the usual effects. The result is that established and compulsive habits of thinking and behaving are interrupted. This gives both abusers and those trying to help them greatly improved opportunities to develop alternative and less damaging attitudes and patterns of behaviour.

Two uncontrolled studies: have given extremely encouraging results in the treatment of cocaine abusers who are resistant to other approaches, including inpatient programmes. Both reports emphasise the importance of informed consent. Patients confirm in writing that they understand the potential dangers of using sympathomimetic drugs like cocaine or amphetamines while taking a monoamine oxidase inhibitor. If deterrents fail, however, and the abuser risks using cocaine, it is reassuring to know that the interactions so far reported have been disagreeable rather than disastrous.

As with naltrexone and disulfiram, the key to successful treatment is careful supervision of the antagonist drug to improve compliance. Both the reported studies used phenelzine in doses ranging from $15 \mathrm{mg}$ on alternate days to $90 \mathrm{mg}$ daily. The ability of this drug to inhibit monoamine oxidase for up to two weeks is a very useful quality, and the need to avoid certain foods probably acts as a reminder. Clearly, treatment with phenelzine should not be undertaken lightly, but, as the authors point out, for some people cocaine abuse is a serious problem and causes mortality and morbidity. If treatment with phenelzine is acceptable in a country as litigious as the United States, we should not spurn it in Britain

The Stapleford Centre. Hanway Clini

COLIN BREWER London WIP 9DF

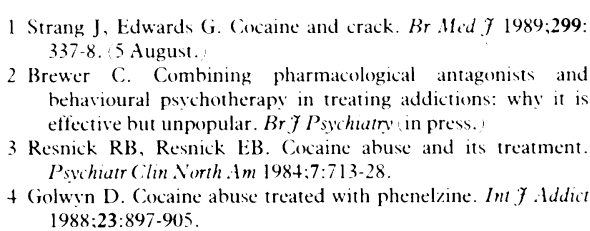

1 Strang J, Edwards G. Cocaine and crack. Br Med f 1989;299: $337-8.5$ August

2 Brewer C. Combining pharmacological antagonists and hehavioural psichotherapy in treating addictions: why it is effective but unpopular. Br.f Psychatry in press.

Resnick RB, Resnick EB. Cocaine abuse and its treatment Psychiatr Clin North \& $m$ 1984:7:713-28.

4 (iolwen D. Cocaine abuse treated with phenelzine. $\operatorname{Im} 7$. dddic 1988:23:897-905

\section{Learning by experience}

SIR, - We have used a procedure very similar to that in the University of Limburg' in our living anatomy laboratories, firstly from 1968 to 1973 in the department of anatomy, University of Iowa, and, latterly, from 1973 in the department of anatomy, University of Nebraska Medical Center.

Each year in the 24 weeks of the anatomy course, and running lockstep with dissection, we have taught physical examination to about 120 medical students, 25 physical therapy students, and 25 physician assistant students. Students practise physical examination on each other. Facilities are provided for practice in these skills, and, yes, breast, rectal, and pelvic examinations are performed, under the supervision of an instructor, in separate cubicles in our anatomy self study suite.

The great majority of these students feel that this class, demonstrated live in the living anatomy laboratory on student pair volunteers, by the same exact procedure, and using medically qualified instructors to ensure that student pairs carry out each examination properly, has been one of the most valuable of all their classes, given as it is when the structures examined are those being dissected in the dissecting room.

NORAH F METCAI.

Department of Anatoms W KENNETH MFTCAI.F

Eniversity of Nchraska

1 Hanson L. Hepersgibbels. Learning by experience. Br. Med 7 989:299:3+6. 15 August

\section{Cervical screening and family practitioner committee registers}

SIR,-It is unfortunate that Mr Peter Dobson seems to have misunderstood the main point of our paper on cervical cytology screening in the inner city: Our criticisms are not levelled at the use of family practitioner committee registers for screening purposes as such. Rather we are questioning their value in inner city districts, particularly in inner London.

We would like to correct Dr Dobson's and $\mathrm{Mr}$ J P Nicholl and colleagues' assertion that no check was made with general practitioners about the accuracy of the addresses. We clearly stated in our article that the prior notification lists were sent to each general practitioner concerned and that amendments were made to the family practitioner committee register in accordance with the information received. Our result of $47 \%$ of letters incorrectly addressed was after this process had taken place. Though some general practitioners may not have completed the prior notification list as thoroughly as we would have liked, further investigation showed that in most cases the changes of address were not known to the general practitioners.

We suggest that the main contributory factor to the inaccuracy of family practitioner committee lists is the high mobility of the population, which is a feature of inner London. At the 1981 census 19\% of the population of Kensington, Chelsea, and Westminster Family Practitioner Committee had moved house in the previous year. This is twice the national average and the highest rate in the country. Unfortunately, people tend not to notify their general practitioners routinely of any change of address, and it seems that many had not registered with another general practitioner. The high population mobility in Kensington, Chelsea, and Westminster contributes to the list inflation rate of $34 \%$, also the highest in the country. This is considerably in excess of the overall average of $6 \%$ cited by Mr Dobson.

We do not understand why $\mathrm{Mr}$ Dobson mentions electoral registers and postcoding with reference to our paper as we made no mention of these.

$\mathrm{Mr}$ Dobson raises another issue, which highlights the need to consider what is happening locally in implementing a call and recall programme-namely, that of the transfer of results between the hospital laboratory and the family practitioner committee. The proximity in inner London of so many health authorities and family practitioner committees in addition to a large commuting population exacerbates the problem of cross boundary flows. One result of this is the impracticability of direct linkage between $\mathrm{St}$ Mary's Hospital and Kensington, Chelsea, and Westminster Family Practitioner Committee because a large proportion of the workload is generated by people living outside not only the health authority but also the committee's area. Although manual transfer of records would seem rather archaic, it works extremely effectively. Alternative methods of transfer are being considered, and we look forward to the day when family practitioner committees are linked with one another. 